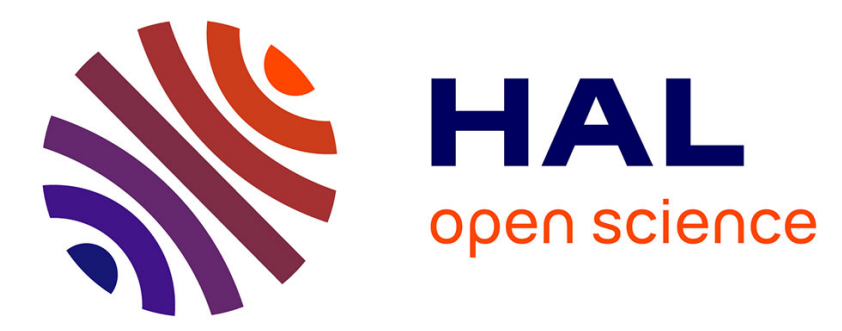

\title{
Nanoscale Crystallization Mechanisms in a GeSSbCsCl Glass Ceramic and Relationships with Mechanical and Optical Properties
}

Alexandre Morvan, E. Lavanant, L. Arnoldi, X. Sauvage, Laurent Calvez, A. Vella, Allisson Saiter

\section{To cite this version:}

Alexandre Morvan, E. Lavanant, L. Arnoldi, X. Sauvage, Laurent Calvez, et al.. Nanoscale Crystallization Mechanisms in a GeSSbCsCl Glass Ceramic and Relationships with Mechanical and Optical Properties. Journal of Physical Chemistry C, 2021, 125 (7), pp.4196-4204. 10.1021/acs.jpcc.0c09889 . hal-03178584

\section{HAL Id: hal-03178584 \\ https://hal.science/hal-03178584}

Submitted on 23 Mar 2021

HAL is a multi-disciplinary open access archive for the deposit and dissemination of scientific research documents, whether they are published or not. The documents may come from teaching and research institutions in France or abroad, or from public or private research centers.
L'archive ouverte pluridisciplinaire HAL, est destinée au dépôt et à la diffusion de documents scientifiques de niveau recherche, publiés ou non, émanant des établissements d'enseignement et de recherche français ou étrangers, des laboratoires publics ou privés. 


\section{Nanoscale crystallization mechanisms in a GeSSbCsCl glass-ceramic and}

relationships with mechanical and optical properties

A. Morvan ${ }^{a}$, E. Lavanant ${ }^{b}$, L. Arnoldi ${ }^{a}$, X. Sauvage ${ }^{a}$, L. Calvez ${ }^{b}$, A. Vella*a,c, A. SaiterFourcin*a.

a Normandie Univ, UNIVROUEN, INSA Rouen, CNRS, Groupe de Physique des Matériaux, 76000 Rouen, France.

${ }^{c}$ Institut Universitaire de France

b Univ Rennes, CNRS, ISCR (Institut des Sciences Chimiques de Rennes) UMR6226, F-35000 Rennes, France.

Corresponding Authors: angela.vella@univ-rouen.fr, allison.saiter@univ-rouen.fr

\section{Abstract}

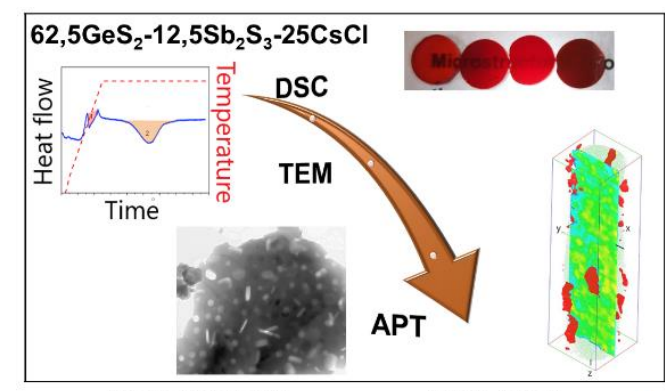

From macro to ............ nano scale

TOC graphic

Crystallisation of a $62,5 \mathrm{GeS}_{2}-12,5 \mathrm{Sb}_{2} \mathrm{~S}_{3}-25 \mathrm{CsCl}$ glass-ceramic was investigated using different techniques from macro to nano-scale. A two-step crystallization process was evidenced, allowing a direct correlation between the microstructural features and the evolution of the mechanical and optical properties. This two-step crystallization process starts with the nucleation of spherical $\mathrm{CsCl}$ crystals that progressively evolve toward a disc shaped morphology when they grow. This transformation goes along with a local enrichment of $\mathrm{Sb}$ leading also to a significant increase of the lattice parameter of the $\mathrm{CsCl}$ phase. These crystals significantly improve the mechanical behaviour of the glass with only a small reduction of the infrared transmission properties. 


\section{1-Introduction}

Chalcogenide glasses (ChG) are able to transmit light from visible to far infrared range and can be easily shaped into complex geometry offering great potential for developing new lenses for infrared cameras and new optical fibres for mid-infrared laser and midinfrared spectroscopy ${ }^{1}$. Moreover, for thermal imaging applications, these materials are considerably cheaper than single crystal germanium or ZnSe polycrystals. However, the main drawback of chalcogenide glasses comes from their weak mechanical properties as compared to oxide glasses. The weaker energy bond $\left(215 \mathrm{~kJ} / \mathrm{mol}\right.$ for $\mathrm{ChG}$ against $800 \mathrm{~kJ} / \mathrm{mol}$ for $\mathrm{SiO}_{2}$ based glasses) gives rise to a lower Young modulus (10 GPa for $\mathrm{ChG}$ against $69 \mathrm{GPa}$ for $\mathrm{SiO}_{2}$ based glasses) and lower toughness $\left(0,3 \mathrm{MPa} / \mathrm{m}\right.$ for $\mathrm{ChG}$ against $0,8 \mathrm{MPa} / \mathrm{m}$ for $\mathrm{SiO}_{2}$ based glasses).

It has been demonstrated that the nucleation of nano crystals inside the glassy matrix, resulting in a glass-ceramic material, could give rise to enhanced mechanical properties while maintaining good optical properties. The range of achievable combination of properties has been studied for various compositions ${ }^{2-5}$.

In 2007, Calvez et al. ${ }^{6}$ highlighted the key role of $\mathrm{CsCl}$ in the controlled crystallization process to form a chalcogenide glass-ceramic based on the composition Ge-Ga-SeCsCl. In 2011, Rozé et al. ${ }^{7}$ produced a chalcogenide glass-ceramic based on the

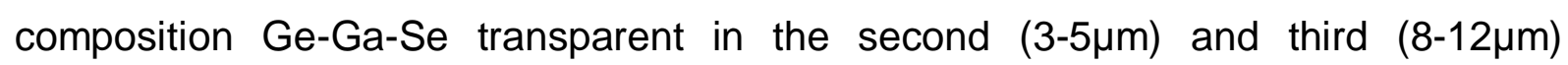
atmospheric windows without using alkali-halide. But in this case the chalcogenide glass-ceramic presented a smaller transparency window and a smaller vitreous domain than those based on the Ge-Ga-Se-CsCl system. In 2009, Ledemi et al. ${ }^{8}$ proposed a Ge-Ga-S-CsCl based glass-ceramic and evidenced that the $\mathrm{CsCl}$ incorporation in the glass allowed obtaining a totally transparent material in the visible range. This work proved the importance of $\mathrm{CsCl}$ in the $\mathrm{Ge}-\mathrm{Ga}-\mathrm{S}-\mathrm{CsCl}$ composition concerning the expected optical properties.

Our work focuses on the glasses and glass-ceramics based on the $\mathrm{Ge}-\mathrm{S}$-Sb-CsCl composition, discovered in 2004 by Zhang et al. ${ }^{9}$ as the first reproducible sulphurbased glass ceramic. More precisely, we focus on the composition $62,5 \mathrm{GeS}_{2}$ $12,5 \mathrm{Sb}_{2} \mathrm{~S}_{3}-25 \mathrm{CsCl}$, optimized by Zhu et al. ${ }^{10}$ in order to improve the fracture toughness and the critical load for crack initiation, and keeping a high optical infrared (IR) transmission. 
Because of the fourfold coordination of $\mathrm{Ge}, \mathrm{GeS}_{2}$ based glasses exhibit higher glass transition temperatures and better mechanical properties than other sulphide glasses ${ }^{4}$. The $\mathrm{Sb}_{2} \mathrm{~S}_{3}$ addition allows obtaining a good glass forming ability ${ }^{11}$, and the $\mathrm{CsCl}$ addition leads to an extended window of transparency and allows to product chalcohalide glass-ceramics with a controlled crystallization ${ }^{2}$.

In the composition $62,5 \mathrm{GeS}_{2}-12,5 \mathrm{Sb}_{2} \mathrm{~S}_{3}-25 \mathrm{CsCl}$, Zhang et al. ${ }^{9}$ and Zhu et al. ${ }^{10}$ have showed the presence of a crystalline phase with a cell parameter close but smaller than that of $\mathrm{CsCl}$ crystal. They suggested a substitution of $\mathrm{Cl}^{-}$by $\mathrm{S}^{2-}$ or/and $\mathrm{Cs}^{+}$by $\mathrm{Ge}^{2+}$. They also highlighted the presence of a second crystal morphology (needle shape) after $31 \mathrm{~h}$ of annealing at $290^{\circ} \mathrm{C}$. These needles, whose composition is not identified, seem to improve mechanical properties.

Thus, as demonstrated in literature, the addition of $\mathrm{CsCl}$ is a key parameter for the production of chalcogenide glass-ceramics, for the improving of mechanical properties, and for the optical properties concerning the transmission in the visible range. This implies a great interest for the understanding of the nanoscaled mechanisms of $\mathrm{CsCl}$ crystallization process ${ }^{8,12-22}$.

In this work, focused on the specific composition mentioned above, a full range of characterization methods has been applied to clarify the exact morphology and composition of nucleated crystals ${ }^{9,10}$. In situ X-Ray diffraction (XRD) data were combined with transmission electron microscopy (TEM), observations atom probe tomography (APT) analyses, classical differential scanning calorimetry (DSC) and modulated temperature differential scanning calorimetry (MT-DSC) analyses to study the crystallization process in terms of crystallinity degree, phase identification and kinetic. BSIdes, an emphasis was also given on the relationship between structural evolutions and mechanical or optical properties. This experimental study performed from macro to nano scale, brings crucial new information about the crystallization dynamic when $25 \%$ (molar) of $\mathrm{CsCl}$ is inserted inside the glass matrix.

\section{2-Experimental}

A chalcogenide $62,5 \mathrm{GeS}_{2}-12,5 \mathrm{Sb}_{2} \mathrm{~S}_{3}-25 \mathrm{CsCl}$ glass was prepared using the classical melt-quenching technique with high purity raw materials (99,999\%: Ge, Sb, Ga, S and $99,9 \% \mathrm{CsCl}$ ) weighed in stoichiometric proportions in a glove box and introduced inside a silica tube. 
The silica tube was evacuated down to $10^{-5} \mathrm{~Pa}$, sealed and placed in a rocking furnace at $850^{\circ} \mathrm{C}$ for $12 \mathrm{~h}$ to homogenize the melt. The melted glass was quenched in water at room temperature, and then annealed $10^{\circ} \mathrm{C}$ below the glass transition range in order to avoid mechanical stress ${ }^{23-25}$.

The evolution of the crystallinity degree was measured by using X-ray diffraction (XRD) at $290^{\circ} \mathrm{C}$ on a Bruker diffractometer with a Co target $(K=1,79 \AA)$ equipped with a furnace. A step width of $0,04^{\circ}$ was used for all the analyses with a scan speed of $1 \mathrm{~s}$ in a $\theta-2 \theta$ mode, and the measures are performed on powdered samples.

The differential scanning calorimetry (DSC) analyses were performed using the DSC STA F449 from Netzsch. Isothermal experiments were performed under a $40 \mathrm{~mL} / \mathrm{min}$ argon gas flow at $350^{\circ} \mathrm{C}$ after a heating ramp at $5 \mathrm{~K} / \mathrm{min}$ from room temperature, with sample masses between 5 and $10 \mathrm{mg}$ inside aluminium pans. The calibration in energy and temperature has been performed with five different standards: $\mathrm{CsCl}, \mathrm{In}, \mathrm{Sn}, \mathrm{Zn}$, $\mathrm{Au}$.

The modulated temperature differential scanning calorimetry (MT-DSC) analyses were performed on a Q100 from TA instrument with a heating rate of $5 \mathrm{~K} / \mathrm{min}$, a modulation amplitude of $\pm 0,796 \mathrm{~K}$ and an oscillation period of 60 s under a $50 \mathrm{~mL} / \mathrm{min}$ nitrogen gas flow. This protocol corresponding to a "heat-only mode" (i.e. the best mode to analyse samples with an ability to crystalize during a heating ramp ${ }^{26}$ ) has been optimized through few experiments, the goal being to highlight the signature of the glass transition. The apparatus has been calibrated in temperature and energy using indium as standard, and in heat capacity using sapphire. All experiments were done with sample masses between 2 and $6 \mathrm{mg}$ inside aluminium pans. The reference and sample pans had identical masses within $+/-0,05 \mathrm{mg}$ to optimize the baseline. The MT-DSC experiments allow extracting all the quantities characterising the glass transition domain, i.e. $T_{g}$ taken at the onset ( $\left.T_{\text {gonset }}\right), T_{g}$ taken at the middle point $\left(T_{\text {gmid }}\right), T_{g}$ taken at the offset ( $\left.T_{\text {goffset }}\right)$, the glass transition range $\left(\Delta T_{g}=T_{\text {goffset }}-T_{\text {gonset }}\right)$, and the heat capacity step taken at $T_{\text {gmid }}\left(\Delta C_{p}\right)$.

The measurements in the mid and far infrared for optical characterizations were performed on a Fourier transform spectrometer (transmission precision of $2 \%$ ). Amorphous and partially crystallized materials were characterized by Transmission Electron Microscopy (TEM) on a JEOL ARM 200F microscope operated at 200kV. Bright field images and selected area electron diffraction (SAED) patterns were recorded with a parallel beam. Additional data were also collected in Scanning TEM 
(STEM) mode with a probe size of $0.2 \mathrm{~nm}$ and a convergence angle of $34 \mathrm{mrad}$. Images were recorded with both a bright field (BF) detector (collection angles 0-45 mrad) and a High-Angle Annular Dark-Field (HAADF) detector (collection angles 68-280 mrad). X-ray Energy Dispersive Spectroscopy (EDS) was carried out with an Oxford Instruments X-max detector (solid angle of $0.7 \mathrm{sr}$ ). Samples were prepared with a three steps procedure: i) mechanical crushing of the glass in a mortar, ii) dispersion of crushed pieces in ethanol and sonication, iii) deposition of a droplet on a TEM grid with a carbon film. TEM observations were carried out in the thinnest areas of fragments that were transparent to electrons.

Atom probe tomography (APT) analyses were performed on a Laser assisted Wide angle Tomographic Atom Probe (LaWaTAP) ${ }^{27-30}$. Samples were prepared by the liftout method by coupling Scanning Electrons Microscopy and Focused Ion Beam (SEM/FIB) and welded on a tungsten tip supported with a Pt-C beam deposition. In order to shape the sample as a needle with a nanometric apex diameter, the FIB annular milling was used ${ }^{30}$. More details on the APT, the analysis conditions and the reconstruction parameters are given in supporting information. 


\section{3-Results and discussion}

\subsection{Macroscopic scale analyses}

The glass transition has been studied by MT-DSC. This experiment allows separating the contributions linked to the heat capacity of the sample (such as the glass transition), from contributions linked to kinetic events (such as the relaxation phenomena, or the cold crystallization). Classical DSC analyses carried out on a similar glass ${ }^{31}$ allowed to determine only the onset of the glass transition because of different thermal events superimposed in the glass transition range. 
(a)
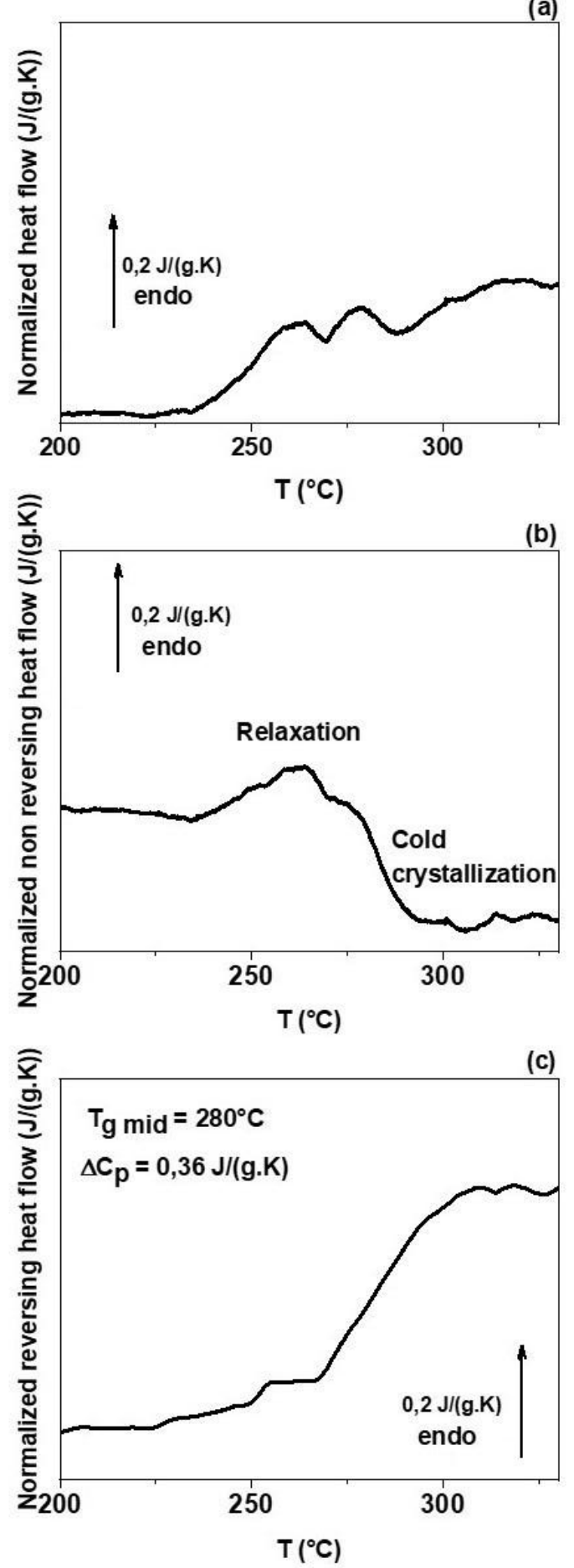

Figure 1. MT-DSC experiments on the amorphous glass. (a) Average heat flow (equivalent to the signal obtained by classical DSC). (b) Non reversing heat flow. (c) Reversing heat flow. All spectra have been normalized to the sample mass.

Figure 1 shows the experimental results obtained by MT-DSC analyses. The normalized heat flow signal (Figure $1(\mathrm{a})$ ) is equivalent to that obtained by classical DSC, and it clearly shows the difficulty to extract from simple DSC data all quantities characterizing the glass transition. Figure 1 (b) shows the normalized non reversing 
heat flow, thus contributions linked to kinetic events. This highlights the structural relaxation phenomenon (endothermic event) near $260^{\circ} \mathrm{C}$, and the cold crystallization process (exothermic event associated to a dynamic crystallization during the heating) occuring in the glass transition range. Figure 1 (c) shows the normalized reversing heat flow, i.e. contributions linked to the heat capacity of the sample such as the glass transition. From this curve, all parameters characterising the glass transition domain have been extracted: $\mathrm{T}_{\text {gonset }}=260^{\circ} \mathrm{C}, \mathrm{T}_{\text {gmid }}=280^{\circ} \mathrm{C}, \mathrm{T}_{\text {goffset }}=300^{\circ} \mathrm{C}, \Delta \mathrm{T}_{\mathrm{g}}=40^{\circ} \mathrm{C}$, and $\Delta \mathrm{C}_{\mathrm{p}}=0,36 \mathrm{~J} /(\mathrm{g} \cdot \mathrm{K})$. We note the $\mathrm{T}_{\text {gonset }}$ value is in good agreement with the previous one obtained in ref ${ }^{31}$.

Then, the crystallization process of this glass was studied at the temperature $T_{\text {gmid }}+$ $10^{\circ} \mathrm{C}$, i.e. $290^{\circ} \mathrm{C}{ }^{9,10}$.

Additionally, the crystallization process was pointed out by an isothermal study performed with classical DSC.

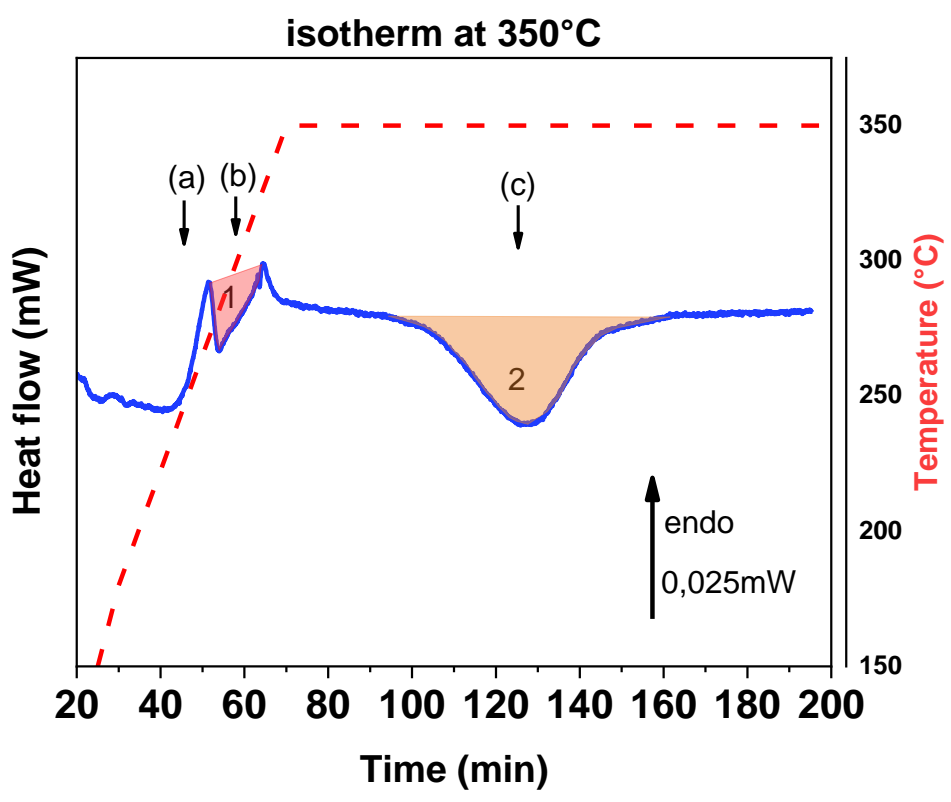

Figure 2. DSC curve obtained during isothermal experiment on the amorphous glass annealed at $350^{\circ} \mathrm{C}$ during 130 minutes; the first 70 minutes corresponding to the heating ramp. (1) Corresponds to the first crystallization occurring in the glass transition region, and (2) to the second and slower crystallization process. (a) Glass transition, (b) first crystallization peak, (c) second crystallization peak.

Figure 2 shows the isotherm curve obtained from this experiment. The glass transition occurs after approximately 40 minutes and a two-step crystallization process is 
highlighted: A first fast crystallization step (b) appears in the glass transition region (a) after approximately 50 minutes, and a second one (c) appears after approximately 100 minutes. We precise that the isotherm was performed at $350^{\circ} \mathrm{C}$ in order to accelerate the second crystallization kinetic.

The crystallization process was also monitored by XRD to identify the structure of crystalline phases that have nucleated, and to estimate the evolution of the crystallinity degree with annealing. 


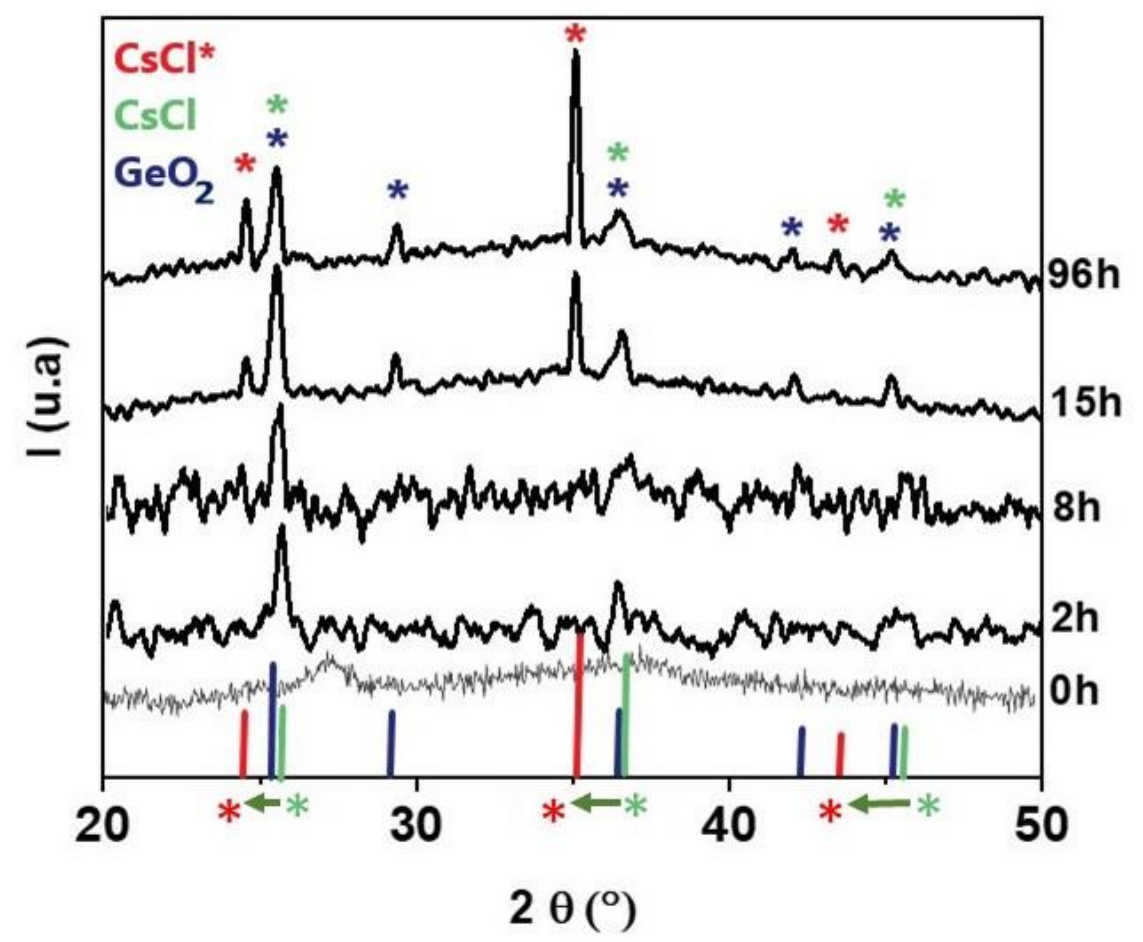

Figure 3. X-ray diffraction patterns for glass crystallized at $290^{\circ} \mathrm{C}$, for different times with the representation of the $\mathrm{GeO}_{2}$ phase, $\mathrm{CsCl}$ (cubic with $a=0.411 \mathrm{~nm}$ ) from the database PDF-2 release 2003 from ICDD (International Centre for Diffraction Data), and $\mathrm{CsCl}^{*}$ corresponding to the classical $\mathrm{CsCl}$ crystalline structure with a larger lattice parameter. The green arrows highlight the corresponding peak shifts toward smaller angles.

Figure 3 displays XRD patterns recorded for the glass after annealing at $290^{\circ} \mathrm{C}$ for different durations. As expected, the initial material (Oh in Figure 3 ) exhibits an amorphous structure. For crystallization times shorter than $15 \mathrm{~h}$, the main detected peak corresponds to the $\mathrm{GeO}_{2}$ phase (indexed in blue and resulting from the sample surface oxidation during the in-situ annealing in air). However, there is also a contribution of the $\mathrm{CsCl}$ phase (indexed in green) for the peaks at $2 \theta \approx 26^{\circ}$ and $2 \theta \approx$ $37^{\circ} \mathrm{C}$. The $\mathrm{Xc}$ measured for times shorter than $15 \mathrm{~h}$ corresponds to the $\mathrm{GeO}_{2}$ and $\mathrm{CsCl}$ phase contributions. To confirm the contribution of $\mathrm{CsCl}$ phase for times shorter than $15 \mathrm{~h}$, TEM observations have been performed on a sample crystallized $9 \mathrm{~h}$ at $290^{\circ} \mathrm{C}$ and are discussed later.

For crystallization times longer than $15 \mathrm{~h}$, peaks corresponding to the classical $\mathrm{CsCl}$ phase with a lattice parameter $a=0.411 \mathrm{~nm}$ clearly appear together with other peaks 
that could be attributed to the same crystallographic structure but slightly shifted to smaller angles i.e. with a larger lattice parameter. From the Bragg's law this new lattice parameter has been estimated $\left(a^{\prime}=0.426 \mathrm{~nm}\right)$ and corresponding to a $3,7 \%$ increase. Such a dilatation of the crystalline structure may result from the insertion of large solute atoms in the $\mathrm{CsCl}$ crystalline structure or by a substitution of $\mathrm{Cl}$ by another element ${ }^{32}$. To quantify the kinetic of the crystallization process, the crystallinity degree $\mathrm{Xc}_{\mathrm{c}}$ has been estimated from XRD data (see Figure 4).

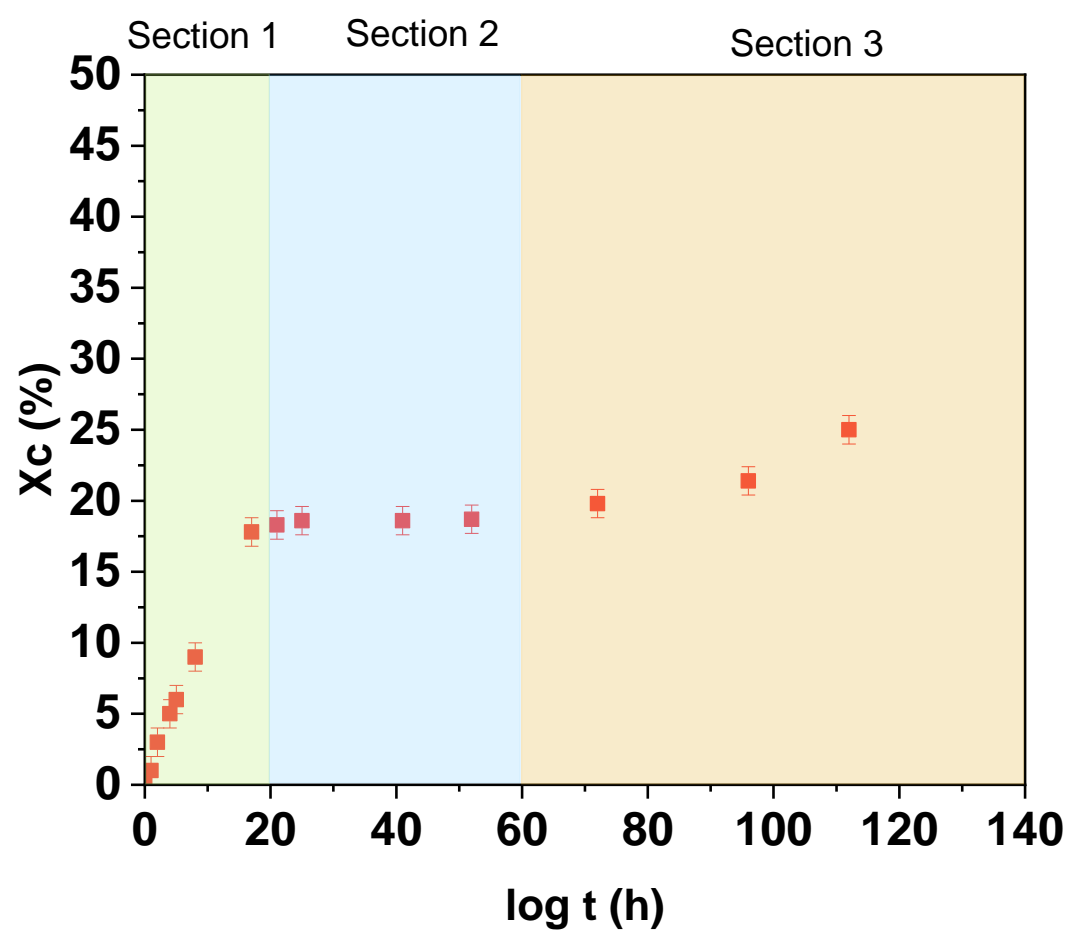

Figure 4. Evolution of the crystallinity degree $(X c)$ as a function of time for the glass annealed at $290^{\circ} \mathrm{C}$.

$\mathrm{Xc}$ is estimated by calculating the ratio between the peak area (associated to the $\mathrm{CsCl}$ and $\mathrm{GeO}_{2}$ contributions) and the full area (crystals + amorphous part) of the spectra. Due to the contribution of impurity phase $\left(\mathrm{GeO}_{2}\right)$, the measure is more qualitative than quantitative, but allows identifying different steps for comparison with mechanical properties. Furthermore, we observed that there is no more $\mathrm{GeO}_{2}$ formation after $15 \mathrm{~h}$. In a first step, a fast crystallization process occurs up to 20 hours (attributed to $\mathrm{CsCl}$ and $\mathrm{GeO}_{2}$, section 1 in Figure 4). Then, a plateau with a constant crystallinity degree is exhibited between 20h and 60h (section 2 in Figure 4). Last, in a third step (duration longer than 60h) the crystallinity degree increases again highlighting a second kinetic of crystallization (attributed to $\mathrm{CsCl}^{*}$ only, section 3 in Figure 4). 
These data are in good agreement with DSC analyses that show two crystallization peaks (labelled a) and b) in Figure 2), and thus indicating also a two-step crystallization process.

The evolution of the mechanical properties (fracture toughness $\mathrm{Kc}$ and the critical load for crack initiation $\mathrm{Pc}$ ) as a function of the annealing time at $290^{\circ} \mathrm{C}$ has been reported by Zhu \& al. for a similar glass (Figure $5,{ }^{10}$ ).

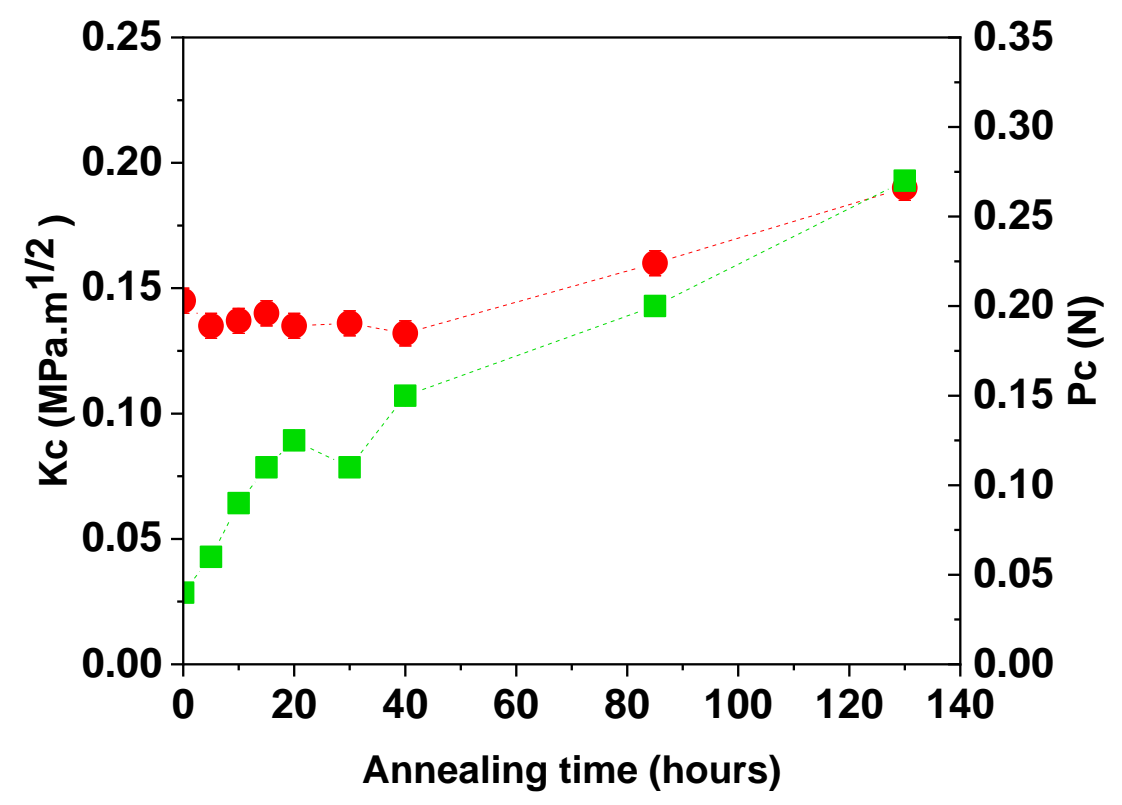

Figure 5. Fracture toughness Kc (red circles) and critical load for crack initiation Pc (green squares) of glass-ceramics obtained by crystallization of the $62,5 \mathrm{GeS}_{2}-$ $12.5 \mathrm{Sb}_{2} \mathrm{~S}_{3}-25 \mathrm{CsCl}$ glass at $290^{\circ} \mathrm{C}$ as a function of annealing time. (adapted from ${ }^{10}$ ).

At first, there is a fast increase of the critical load for crack initiation up to $20 \mathrm{~h}$ together with a relatively constant fracture toughness. Then, after $40 \mathrm{~h}$ both mechanical properties increase linearly up to $140 \mathrm{~h}$. This two-stage evolution seems fully consistent with the two-step crystallization process revealed by XRD (Figure 4) and DSC (Figure 2). The first increase of the critical load for crack initiation is related to the $X_{c}$ increase in the same time range. Then a more stable between 20 and 40 hours is observed. The second increase after 40 hours where the fracture toughness and the critical load for crack initiation also increase can be related to the second $X_{c}$ increase observed after $50 \mathrm{~h}$ of annealing. 
The optical transmission can also be impacted by the crystallization ${ }^{33}$, therefore infrared transmission spectra were recorded to check if a two-stage behaviour could also be detected during annealing at $290^{\circ} \mathrm{C}$ (Figure 6).

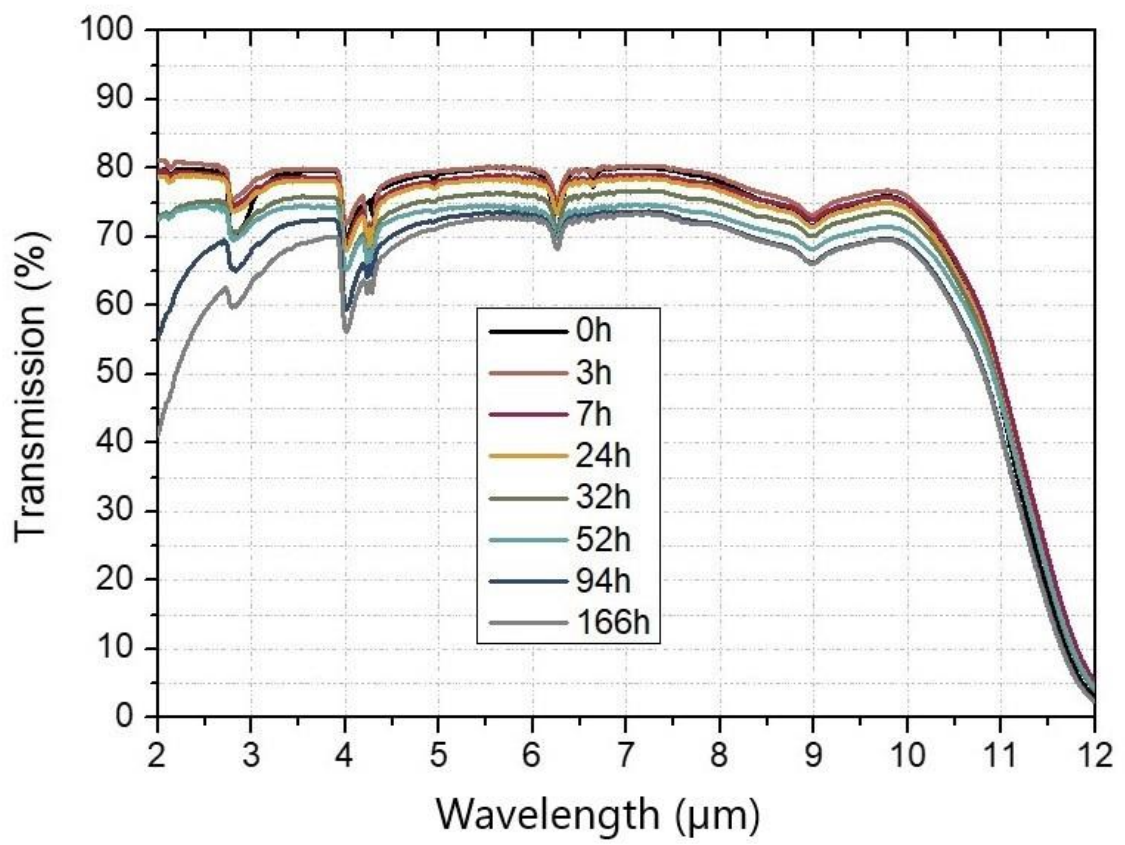

Figure 6. Infrared transmission spectra of the glass-ceramic crystallized at $290^{\circ} \mathrm{C}$ for different times ranging from $0 \mathrm{~h}$ up to $166 \mathrm{~h}$.

During the first hours of crystallization $(<24 \mathrm{~h})$ the optical transmission is relatively constant, but for annealing times longer than $32 \mathrm{~h}$ transmission losses due to Rayleigh scattering progressively appear for short wavelengths indicating significant structural changes such as the crystallinity degree exhibited by XRD analyses (Figure 4).

Thus, we can conclude that it is possible to improve the mechanical properties of the $62,5 \mathrm{GeS}_{2}-12,5 \mathrm{Sb}_{2} \mathrm{~S}_{3}-25 \mathrm{CsCl}$ based glass-ceramics by generating particles without affecting the mid-IR transparency meaning the $8-12 \mu \mathrm{m}$ region, and slightly modifying the second band between 3-5 $\mu \mathrm{m}$. 


\subsection{Nano-scale analyses}

To visualize crystals that have nucleated in the amorphous phase during annealing at $290^{\circ} \mathrm{C}$, TEM observations were carried out (Figure 7).
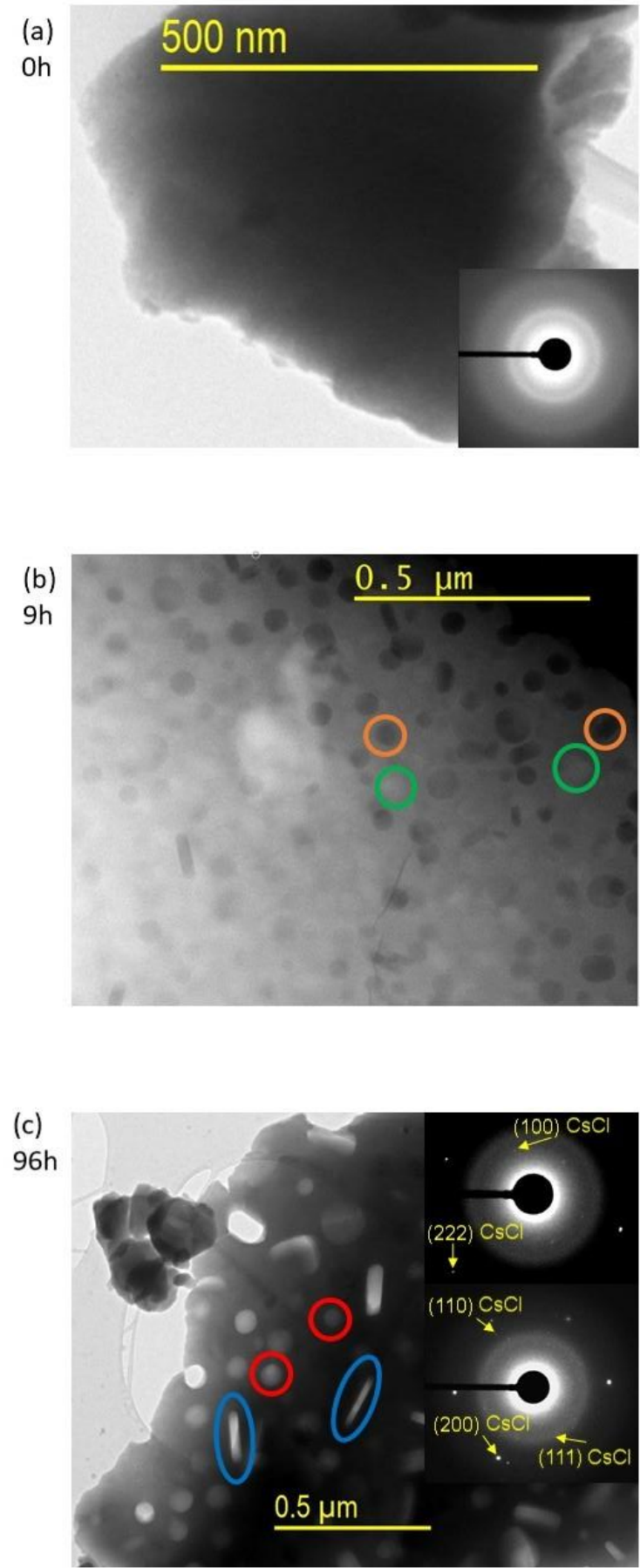

Figure 7. TEM images on the glass-ceramics crystallized for different times at $290^{\circ} \mathrm{C}$. (a) TEM bright field image and corresponding SAED pattern (inset) of the initial amorphous glass, (b) STEM-HAADF image of the glass-ceramic crystallized $9 \mathrm{~h}$ at 
$290^{\circ} \mathrm{C}$ (Dissolved crystals exhibiting dark contrasts are circled in orange and remaining crystals with a bright contrast are circled in green, see text for details),

(c) TEM bright field image and two typical SAED patterns (inset) of the glass-ceramic crystallized during $96 \mathrm{~h}$ at $290^{\circ} \mathrm{C}$ (with spherical crystals in red circles and plate shaped crystals in blue ellipses). All spots on SAED patterns could be indexed with interplanar spacings corresponding to the $\mathrm{CsCl}$ phase, few of them have been arrowed.

As expected for the initial amorphous material, the SAED pattern only exhibits a typical diffuse ring (Figure $7(\mathrm{a})$ ). After $9 \mathrm{~h}$ and $96 \mathrm{~h}$ of annealing at $290^{\circ} \mathrm{C}$, nanoscaled crystals that have homogeneously nucleated within the amorphous matrix clearly appear on the HAADF STEM image (Figure 7(b)). Since the $\mathrm{CsCl}$ crystalline phase is expected to nucleate, these crystals should be brightly imaged on HAADF images (high atomic number of $\mathrm{Cs}$ ), however some crystals with a dark contrast clearly appear, especially near the edge (top right corner of Figure 7(b)). In fact, these dark contrasts (shown in orange circles) are holes due to the dissolution of the $\mathrm{CsCl}$ crystal in the solvent used for the sample preparation, and crystals embedded in the matrix hardly appear with a bright contrast in the matrix (shown in green circles). The small cavities left by dissolved crystals are also clearly seen on the TEM bright field image in Figure 7(c), near the sample edge located on the left side. Anyway, in these samples, two very specific morphologies could be identified, namely discs and rods (represented in red and blue respectively in the Figure 7 (c)). These images are 2D projections of threedimensional features, and depending on its specific orientation, a plate shaped particle for example could appear as a disc or as a rod. In the present material, crystals should have a random orientation and since a very large proportion of discs could be observed (especially for short annealing times), it is believed that two kinds of crystal morphology have grown during the crystallization, namely spheres and plate shaped. In agreement with XRD analyses, the diffraction spots that appear on SAED patterns could only be attributed to the $\mathrm{CsCl}$ phase (Figure 7 (c)), indicating that all crystals have the same crystalline structure. It should be however noted that the lattice parameter changes of $\mathrm{CsCl}$ revealed by XRD are too small to be accurately measured on SAED patterns.

The mean crystal size has been measured for each morphology for different annealing times (see supporting information for TEM data after $10 \mathrm{~min}$ and $1 \mathrm{~h}$ of annealing at $290^{\circ} \mathrm{C}$ ) to plot the evolution of the respective volume fraction and average equivalent diameter (Figure 8). For plate shape crystals, the equivalent diameter corresponds to 
that of a sphere with the same volume. It clearly shows that for short time annealing, only spheres have grown, while an increase of the annealing time leads to a progressive increase of the volume fraction of plate shaped crystals (Figure 8(a)).

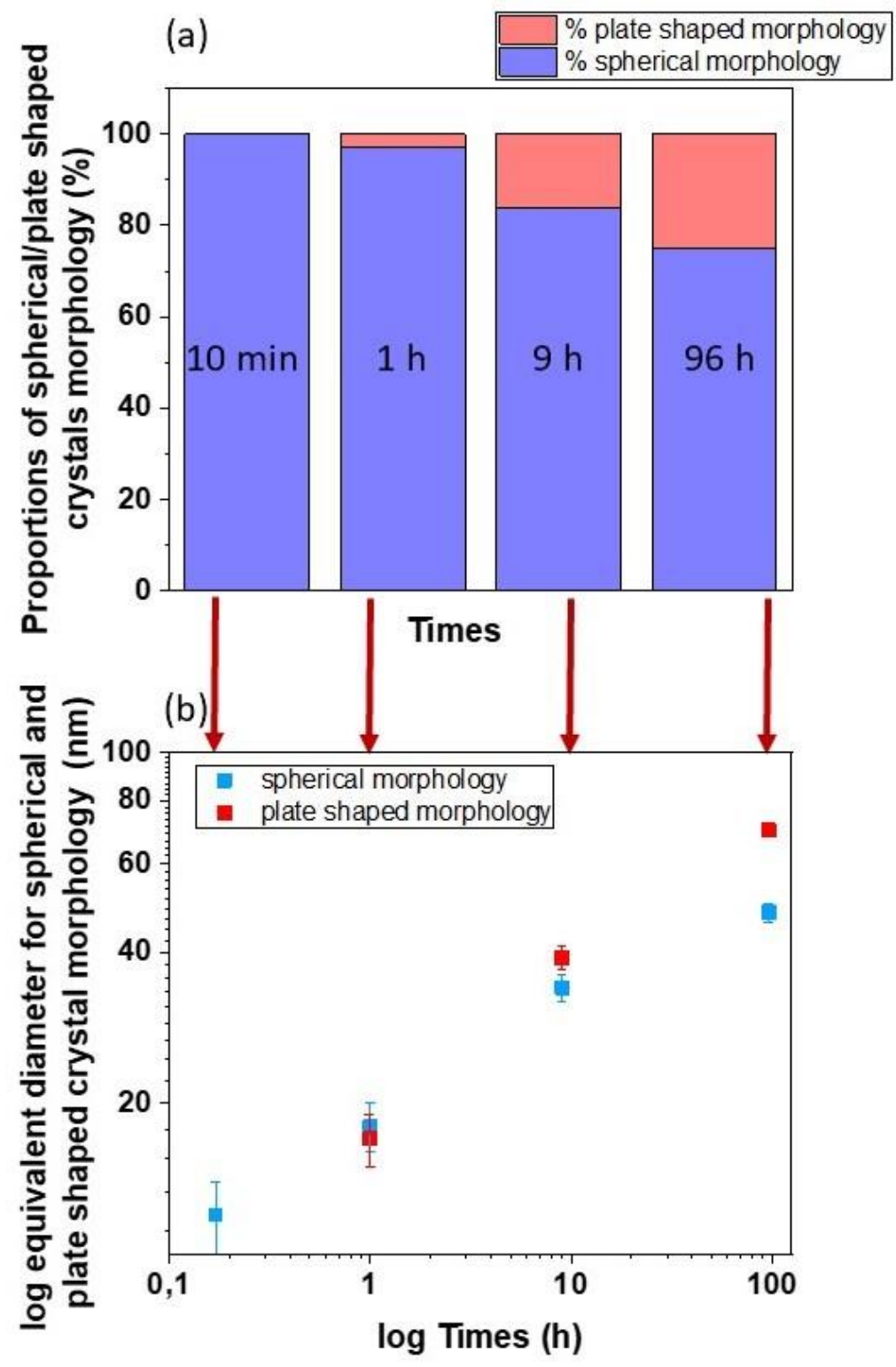

Figure 8. Comparison between spherical and plate shaped morphologies. (a) Proportions of crystals in each morphology, (b) diameter of spherical crystals and equivalent diameter (see text for details) of plate shaped crystals measured.

The mean size of spherical and plate shaped crystals are relatively similar and they both increase with the annealing time (Figure $8(b)$ ). This indicates that the overall volume fraction of crystalline phase increases as observed by in-situ XRD (Figure (4)). At $96 \mathrm{~h}$, the equivalent diameter of the plate shaped crystals becomes however 
significantly larger than spheres, indicating a less favourable growth rate for this latter morphology.

The composition of crystals was measured using EDS for a crystallization time of $9 \mathrm{~h}$ (Figure 9).

(a)

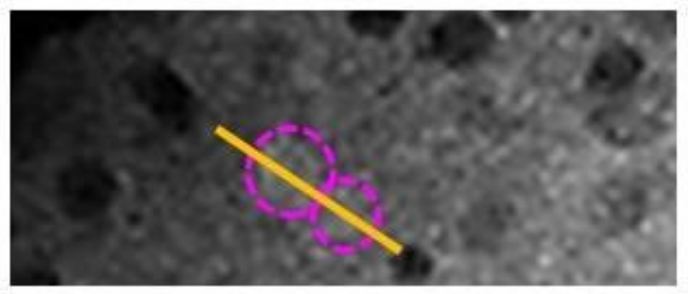

$$
250 \mathrm{~nm}
$$

(b)

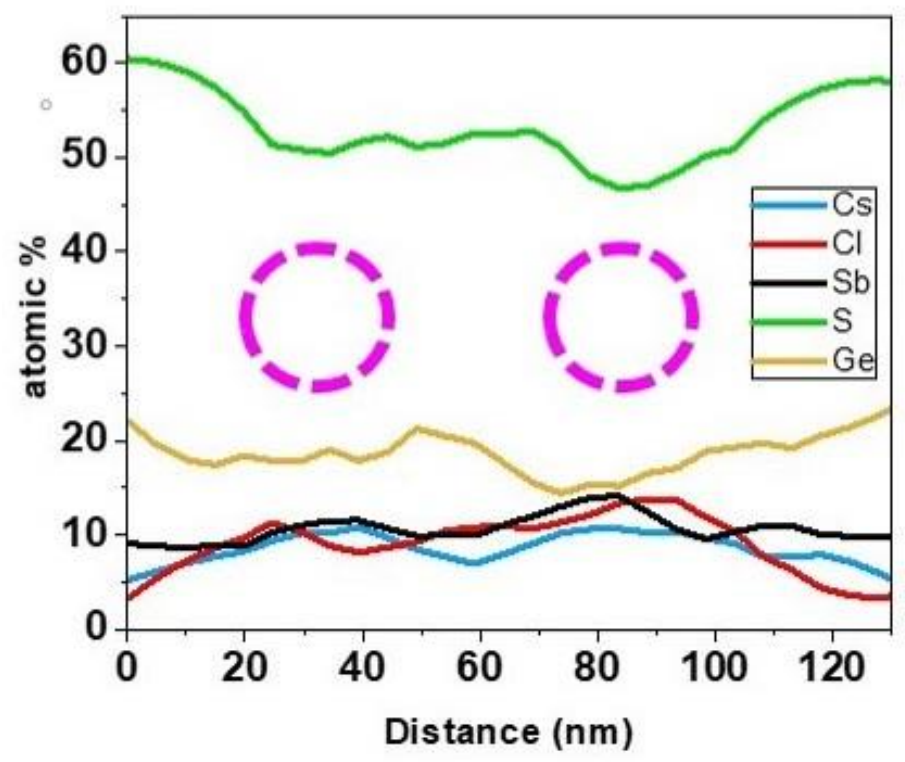

Figure 9. Glass-ceramic crystallized 9h at $290^{\circ} \mathrm{C}$ : (a) STEM HAADF image, EDS line profile analysis was carried out along the yellow line crossing two spherical crystals (purple circles). (b) EDS line profile along the yellow line in (a) showing an increase of the local concentration of $\mathrm{Cs}, \mathrm{Cl}$ and $\mathrm{Sb}$ where the crystals are met (purple circles).

Figure 9 (a) shows an HAADF-STEM image of the glass-ceramic crystallized $9 \mathrm{~h}$ at $290^{\circ} \mathrm{C}$. Dark discs are dissolved $\mathrm{CsCl}$ crystals and an EDS line profile analysis was carried out along the yellow line that intercepts two crystals embedded in the matrix (purple circles). The collected profile (Figure 9 (b)) exhibits a local increase of Cs and 
$\mathrm{Cl}$ concentrations as expected for $\mathrm{CsCl}$ crystals, and also an increase of $\mathrm{Sb}$ concentration (this evolution is discussed later). Then, it demonstrates that even if not detected thanks to XRD (Figure 3), $\mathrm{CsCl}$ crystals start to nucleate in the first hours of annealing at $290^{\circ} \mathrm{C}$.

Similar measurements were performed across crystals with different morphologies in the glass-ceramic crystallized $96 \mathrm{~h}$ at $290^{\circ} \mathrm{C}$ (Figure 10).

STEM Dark Field imaging

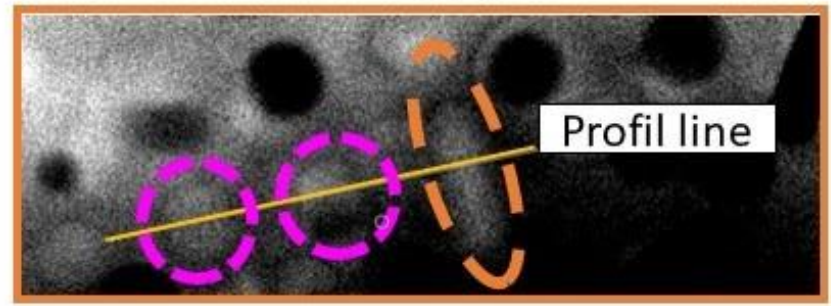

$250 \mathrm{~nm}$

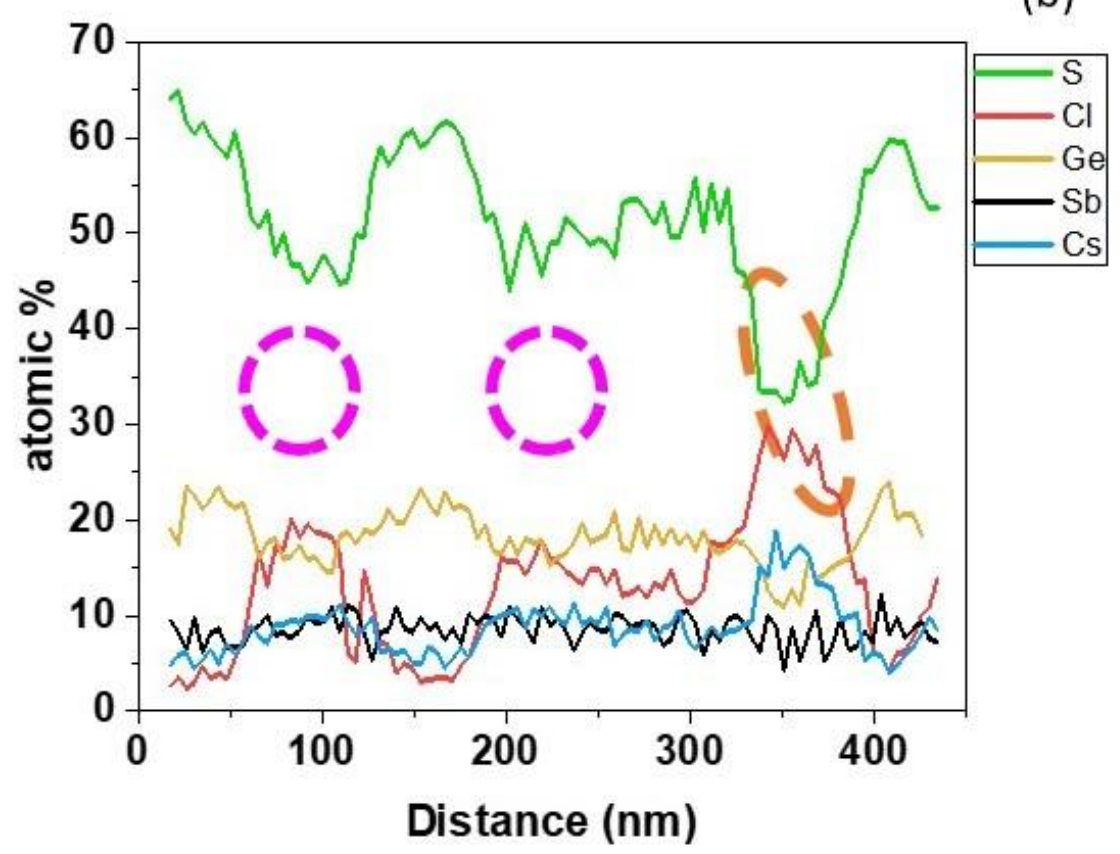

(b)

(a) 
to one as expected for the $\mathrm{CsCl}$ stoichiometry. However, it clearly appears that the matrix contribution (mostly conveyed by the $S$ signal) is smaller for the plate shaped crystal (circled in orange). This feature confirms that it is a disc shaped crystal and not a rod. Indeed, in this later case, the overlap with the matrix contribution should be similar to the spherical shape crystals which is obviously not the case.

The EDS line profile (Figure 10 (b)) shows a Sb atomic concentration almost constant. Considering that the sample thickness is constant between the different morphologies, a decrease of $\mathrm{Sb}$ atomic concentration was expected through the disc-shape morphology (less matrix overlapping). Thus, these data seem to indicate that plate shaped crystals are enriched in $\mathrm{Sb}$ which is consistent with XRD (Figure 3) data showing a lattice expansion for longer aging times where the volume fraction of plate shaped crystals is larger.

To localize more precisely $\mathrm{Sb}$ atoms in $3 \mathrm{D}$, a sample crystallized during $96 \mathrm{~h}$ at $290^{\circ} \mathrm{C}$ was analysed by APT. 

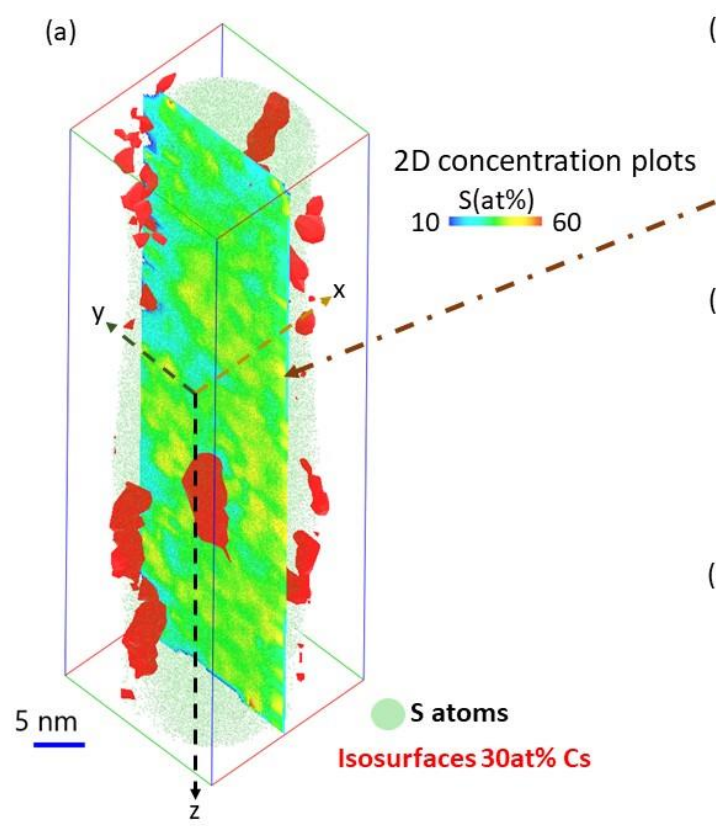

(b)

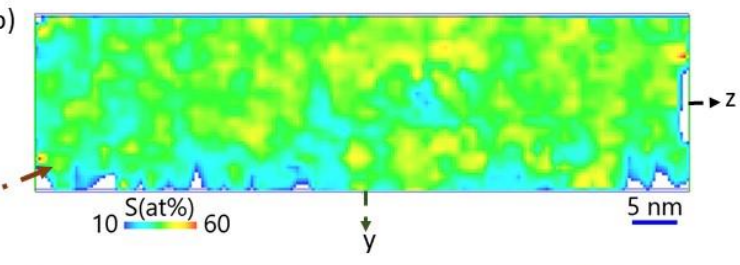

(c)

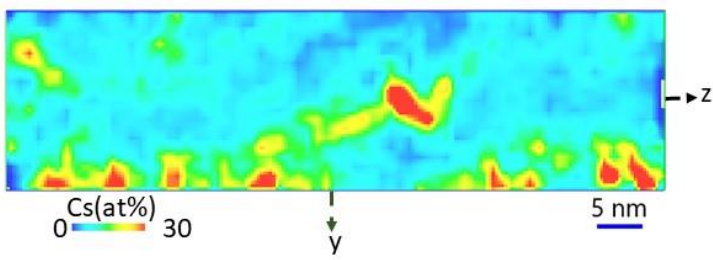

(d)

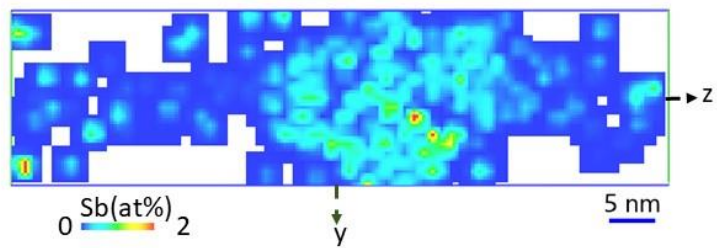

Figure 11. (a) APT 3D reconstruction of the glass-ceramic crystallized for $96 \mathrm{~h}$ at $290^{\circ} \mathrm{C}$ showing the distribution of $S$ (green dots), its inhomogeneity by 2-D concentration plot in the $(y, z)$ plane and the presence of high-concentration Cs regions by isoconcentration surfaces of 30 at. $\%$ Cs (red surfaces). $2 D$ concentration plot in the $(y, z)$ plane of $S(b), C s(c)$ and $S b(d)$.

The APT analysis of chalcogenide glasses ceramics is challenging because they are highly-sensitive materials. In particular, the use of FIB lift-out and annular milling for specimen preparation causes structural damages and chemical degradation which strongly decreases the yield of the analysis and the quantitativity of the composition measurements ${ }^{34}$. Moreover, the possible field-evaporation of neutral and/or negative charged and/or too heavy molecules causes the loss of halides during the detection process ${ }^{35,36}$.

More than 10 specimens of glass crystallized during $96 \mathrm{~h}$ at $290^{\circ} \mathrm{C}$ were analysed by APT eight of them fractured at the beginning of the analysis due to the huge electrostatic stress ${ }^{37}$. For two of them about 2 million of ions were detected.

The mass spectrum associated to one of these successful analyses, reported in the supporting information, shows numerous peaks and confident assignment of chemical identity of all the peaks is extremely difficult. Therefore, quantitative composition measurements are impossible. However, 3D distribution of the main elements can be performed, except for $\mathrm{Cl}$ and $\mathrm{Ge}$. In fact, overlap exist between ${ }^{35} \mathrm{Cl}^{+}\left({ }^{37} \mathrm{Cl}^{+}\right)$and ${ }^{70} \mathrm{Ge}^{2+}$ 
$\left({ }^{74} \mathrm{Ge}^{2+}\right)$, respectively. Accounting for the natural abundance of $\mathrm{Ge}$ isotopes and assuming that peaks at 36 and $38 \mathrm{Da}$ are associated only to $\mathrm{Ge}^{2+}$, the relative amount of $\mathrm{Cl}$ and $\mathrm{Ge}$ can be calculated but the two species will be mixed in the 3D representation ${ }^{38}$.

Therefore, in Figure 11(a) we report only the 3D distribution of S coupled with element envelope map (or iso-concentration surface) of 30 at.\% Cs which clearly reveals the inhomogeneities of $\mathrm{Cs}$ ions distribution. Moreover, the 2-D concentration plot of $\mathrm{S}$ on the $(y, z)$ plane is used to highlights the inhomogeneities of $S$ distribution.

From the 2D-concentration plots of $S$ and $C$ s reported in Figure 11 (b) and (c), respectively, the high-concentration regions of Cs appear to correspond to the lowconcentration regions of $S$ and can be associate to the crystalline phase. The 2Dconcentration plots of $\mathrm{Sb}$, shown in Figure 11 (d), reveals a higher concentration close to the crystalline phase.

In order to study the Sb penetration inside this phase, we select Cs-rich precipitates using a cluster selection based on the "Isoposition method" (IPM) with a concentration threshold of $15 \%$ at $\mathrm{Cs}^{39}$, then erosion concentration profiles across the precipitate's interfaces were plotted using the protocol presented in Ref ${ }^{40}$.

Figure 12 (a) shows the 3D reconstruction of one of these Cs-rich precipitates. The shape of the precipitates is far from a spherical or a disc shape due to the image distortions introduced due to the local magnification effects ${ }^{38}$.

Figure 12 (b) shows the concentration profiles across the interface of the selected precipitate. Inside the precipitate the amount of $\mathrm{Cs}$ and $\mathrm{Sb}$ is higher than in the matrix, on the contrary, the $S$ concentration is lower. Similar behavior was reported on others precipitates, as discussed in the supporting information. 
(a)

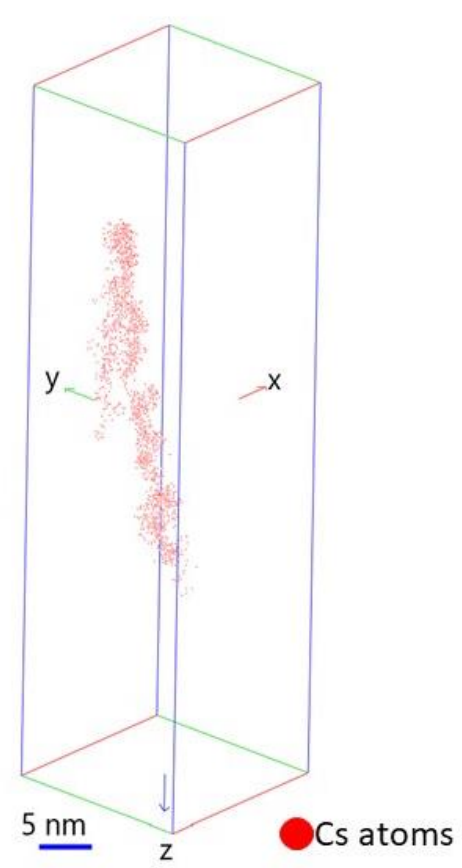

(b)

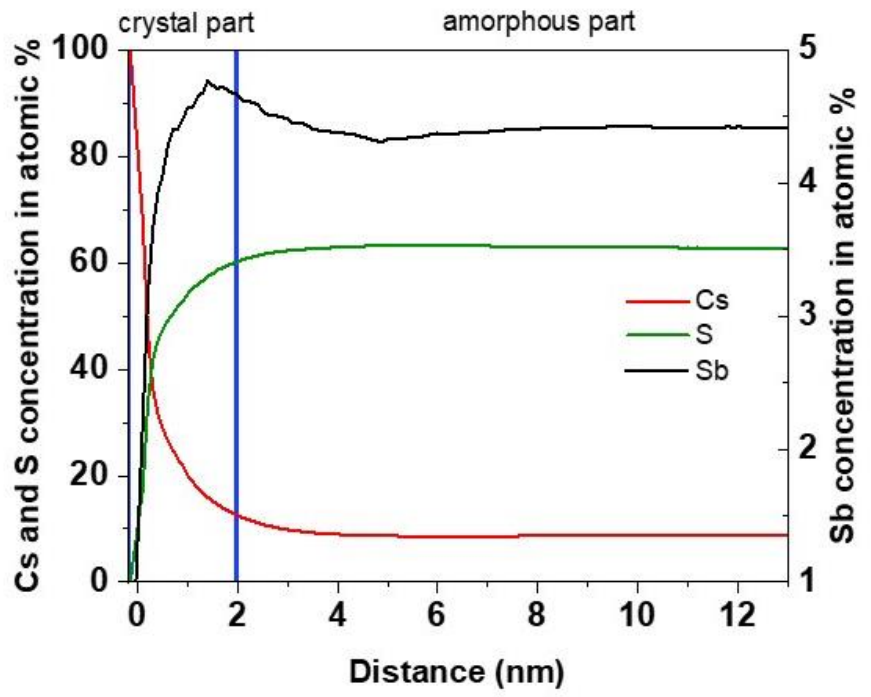

Figure 12. (a) 3D representation of one Cs-rich precipitate after the IPM cluster selection (b) Erosion profile on the Cs-rich precipitate represented in (a), showing the enrichment on Cs and Sb within the precipitate.

These results confirm the presence of some $\mathrm{Sb}$ atoms close to the $\mathrm{CsCl}$ crystal and in inhomegeneous distribution in the matrix. More evidence is needed to conclude on the insertions of $\mathrm{Sb}$ atoms inside the $\mathrm{CsCl}$ crystals. These insertions can lead to an elastic anisotropy or an anisotropy of the surface energy, which could be at the origin of the growth of the original $\mathrm{CsCl}$ crystals in a disc shaped morphology. 


\section{4-Conclusions}

This study, focused on the glass-ceramics based on the $62,5 \mathrm{GeS}_{2}-12,5 \mathrm{Sb}_{2} \mathrm{~S}_{3}-25 \mathrm{CsCl}$ composition, has been divided in two parts. The first part concerns the macroscopic scale analyses by DSC, MT-DSC, and XRD. DSC analyses highlight a crystallization in two steps, the first one appearing during the glass transition and a second one appearing slowly with time at higher temperature. XRD analyses allow determining the crystallinity degree evolution and the nature of the crystal phases. The early formation of $\mathrm{GeO}_{2}$ phase at the surface and the $\mathrm{CsCl}$ phase are observed for short crystallization times. After $15 \mathrm{~h}$ of annealing at $290^{\circ} \mathrm{C}$, the signature of $\mathrm{CsCl}$ peaks shifts to smaller angle, highlighting the dilatation of the crystalline structure. These first results were correlated with the evolution of mechanical properties, which exhibit also evolutions in two steps.

The second part concerns the nano scale analyses of the microstructure evolution during annealing by TEM and APT. Two morphologies of crystals were identified and TEM-EDS analyses confirm that both have a CsCl based composition. APT and TEMEDS analyses show the insertion of some $\mathrm{Sb}$ atoms inside the crystalline structure, implying a structural anisotropy and leading to a disc shaped morphology in opposition with the hypothesis of needle crystals in ref ${ }^{10}$. The cell dilatation can be correlated to the $\mathrm{Sb}$ atoms inserted inside the crystalline structure (ionic radius of $\mathrm{Sb}$ atoms is bigger than the size of the interstitial sites of $\mathrm{CsCl}$, so his insertion leads to an increase of the cell parameter) or to a $\mathrm{Sb}$ substitution with a smaller atom of the structure (which will also imply an increase of the cell parameter).

To resume, the first kinetic in the crystallization process corresponds to the growth of spherical and disc shaped crystals that improve the critical load for crack initiation. After $40 \mathrm{~h}$ of annealing at $290^{\circ} \mathrm{C}$, disc shaped crystals grow faster than spherical ones and, after $96 \mathrm{~h}$ of annealing, they exhibit a larger equivalent diameter than the spherical shape crystals. This second morphology is responsible for the second kinetic in the crystallization process and improves the fracture toughness of the glass-ceramic. The same evolution is observed for the optical properties between 2 and $3 \mu \mathrm{m}$ with a slight decrease of the IR transmission during the first hours. The increase of the disc shaped crystal size after $40 \mathrm{~h}$ induces larger scattering and loss transparency. In order to confirm the formation of $\mathrm{CsCl}: \mathrm{Sb}$ crystals, more evidence by other characterization techniques are still needed such as Raman analysis for example. 


\section{Associated Content}

\section{Supporting information}

APT and Experimental condition analyses.

TEM images on the glass-ceramic crystallized $10 \mathrm{~min}$ and $1 \mathrm{~h}$ at $290^{\circ} \mathrm{C}$.

Mass spectrum for the $62.5 \mathrm{GeS}_{2}-12,5 \mathrm{Sb}_{2} \mathrm{~S}_{3}-25 \mathrm{CsCl}$ glass-ceramic crystallized during $96 \mathrm{~h}$ at $290^{\circ} \mathrm{C}$ with the identified ionic species.

Another example of ATP 3D reconstruction of a new volume of the glass-ceramic crystallized for $96 \mathrm{~h}$ at $290^{\circ} \mathrm{C}$ and the 3D representation of one Cs-rich precipitate after the IPM cluster selection with erosion profile on the Cs-rich precipitate represented showing the enrichment on $\mathrm{Cs}$ and $\mathrm{Sb}$ within the precipitate.

\section{Acknowledgements}

The authors are grateful to the European Union and the Normandy Region for the financial support given to the MAGMA project via the "Fonds Européens de Développement régional" (FEDER). 


\section{References}

(1) Rogalski, A. Infrared Detectors: An Overview. Infrared Physics 2002, 24.

(2) Ma, H; Calvez, L.; Bureau, B.; Le Floch, M.; Zhang, X.; Jacques, L. Crystallization Study of Infrared Transmitting Glass Ceramics Based $\mathrm{On} \mathrm{GeS}_{2}-\mathrm{Sb}_{2} \mathrm{~S}_{3}-\mathrm{CsCl}$. Journal of Physics and Chemistry of Solids 2007, 68 (5-6), 968-971. https://doi.org/10.1016/j.jpcs.2007.01.002.

(3) Lin, C.; Calvez, L.; Rozé, M.; Tao, H.; Zhang, X.; Zhao, X. Crystallization Behavior of $80 \mathrm{GeS}_{2}$ - $20 \mathrm{Ga}_{2} \mathrm{~S}_{3}$ Chalcogenide Glass. Applied Physics A 2009, 97 (3), 713-720. https://doi.org/10.1007/s00339-009-5304-1.

(4) Xia, F.; Zhang, X.; Ren, J.; Chen, G.; Ma, H.; Adam, J. L. Glass Formation and Crystallization Behavior of a Novel GeS2-Sb2S3-PbS Chalcogenide Glass System. Journal of the American Ceramic Society 2006, 89 (7), 2154-2157. https://doi.org/10.1111/j.1551-2916.2006.01058.x.

(5) Zhang, X. H.; Calvez, L.; Seznec, V.; Ma, H. L.; Danto, S.; Houizot, P.; Boussard-Plédel, C.; Lucas, J. Infrared Transmitting Glasses and Glass-Ceramics. Journal of Non-Crystalline Solids 2006, 352 (23-25), 2411-2415. https://doi.org/10.1016/j.jnoncrysol.2006.03.029.

(6) Calvez, L.; Ma, H.-L.; Lucas, J.; Zhang, X.-H. Selenium-Based Glasses and Glass Ceramics Transmitting Light from the Visible to the Far-IR. Advanced Materials 2007, 19 (1), 129-132. https://doi.org/10.1002/adma.200601962.

(7) Rozé, M.; Calvez, L.; Hubert, M.; Toupin, P.; Bureau, B.; Boussard-Plédel, C.; Zhang, X.-H. Molded Glass-Ceramics for Infrared Applications: Molded Glass-Ceramics for Infrared Applications. International Journal of Applied Glass Science 2011, 2 (2), 129-136. https://doi.org/10.1111/j.2041-1294.2011.00037.x.

(8) Ledemi, Y.; Bureau, B.; Calvez, L.; Floch, M. L.; Rozé, M.; Lin, C.; Zhang, X. H.; Allix, M.; Matzen, G.; Messaddeq, Y. Structural Investigations of Glass Ceramics in the $\mathrm{Ga}_{2} \mathrm{~S}_{3}-\mathrm{GeS}_{2}$ -CsCl System. The Journal of Physical Chemistry B 2009, 113 (44), 14574-14580. https://doi.org/10.1021/jp905649v.

(9) Zhang, X.; Ma, H; Lucas, J. A New Class of Infrared Transmitting Glass-Ceramics Based on Controlled Nucleation and Growth of Alkali Halide in a Sulphide Based Glass Matrix. Journal of Non-Crystalline Solids 2004, 337 (2), 130-135. https://doi.org/10.1016/j.jnoncrysol.2004.03.119.

(10) Zhu, S.; Ma, H.; Calvez, L.; Zhang, X.; Lucas, J.; Adam, J.-L.; Shang, H.; Rouxel, T. Optical and Mechanical Properties of Far Infrared Transmitting Glass-Ceramics. Journal of NonCrystalline Solids 2007, 353 (13-15), 1298-1301. https://doi.org/10.1016/j.jnoncrysol.2006.10.075.

(11) Petit, L.; Carlie, N.; Adamietz, F.; Couzi, M.; Rodriguez, V.; Richardson, K. C. Correlation between Physical, Optical and Structural Properties of Sulfide Glasses in the System $\mathrm{Ge}-\mathrm{Sb}-\mathrm{S}$. Materials Chemistry and Physics 2006, 97 (1), 64-70. https://doi.org/10.1016/j.matchemphys.2005.07.056.

(12) Lin, C.; Calvez, L.; Bureau, B.; Ledemi, Y.; Xu, Y.; Tao, H.; Zhang, X.; Zhao, X. Controllability Study of Crystallization on Whole Visible-Transparent Chalcogenide Glasses of GeS2-Ga2S3-CsCl System. journal of optoelectronics and advanced materials, Vol. 12, No. 8, August 2010, p. 1684 - 1691.

(13) Ledemi, Y.; Calvez, L.; Rozé, M.; Zhang, X. H.; Bureau, B.; Poulain, M.; Messaddeq, Y. Totally Visible Transparent Chloro - Sulphide Glasses Based on Ga2S3 - GeS2 - CsCl. journal of optoelectronics and advanced materials, Vol. 9, No12, December 2007, p. 3751 - 3755.

(14) Masselin, P.; Le Coq, D.; Calvez, L.; Petracovschi, E.; Lépine, E.; Bychkov, E.; Zhang, X. $\mathrm{CsCl}$ Effect on the Optical Properties of the 80GeS2-20Ga2S3 Base Glass. Applied Physics A 2012, 106 (3), 697-702.

(15) Hua Zhang, Q. N.; Hua Zhang, Q. N. CsCl Effected Ultrafast Third-order Optical Nonlinearities of GeS2-Sb2S3 Chalcogenide Glasses. J. Mater. Sci. Technol. 2009, 25 (06), 772-776.

(16) Tao, H.; Lin, C.; Chu, S.; Mao, S.; Gong, Y.; Zhao, X.; Wang, S.; Gong, Q. New Chalcohalide Glasses from the GeS2-In2S3-CsCl System. Journal of Non-Crystalline Solids 2008, 354 (12), 1303-1307. https://doi.org/10.1016/j.jnoncrysol.2007.01.103. 
(17) Xu, W.; Ren, J.; Chen, G. Glass Transition Kinetics and Crystallization Mechanism in Ge-GaS-CsCl Chalcohalide Glasses. Journal of Non-Crystalline Solids 2014, 398-399, 42-47. https://doi.org/10.1016/j.jnoncrysol.2014.04.023.

(18) Calvez, L.; Ma, H. L.; Lucas, J.; Zhang, X. H. Glasses and Glass-Ceramics Based on GeSe2$\mathrm{Sb} 2 \mathrm{Se} 3$ and Halides for Far Infrared Transmission. Journal of Non-Crystalline Solids 2008, 354 (12), 1123-1127. https://doi.org/10.1016/j.jnoncrysol.2007.01.100.

(19) Lavanant, E.; Calvez, L.; Cheviré, F.; Rozé, M.; Hingant, T.; Proux, R.; Guimond, Y.; Zhang, X.-H. Radial Gradient Refractive Index (GRIN) Infrared Lens Based on Spatially Resolved Crystallization of Chalcogenide Glass. Optical Materials Express 2020, 10 (4), 860. https://doi.org/10.1364/OME.383868.

(20) Rozé, M.; Calvez, L.; Ledemi, Y.; Allix, M.; Matzen, G.; Zhang, X.-H. Optical and Mechanical Properties of Glasses and Glass-Ceramics Based on the Ge-Ga-Se System. Journal of the American Ceramic Society 2008, 91 (11), 3566-3570. https://doi.org/10.1111/j.15512916.2008.02684.X.

(21) Lin, C.; Li, Z.; Ying, L.; Xu, Y.; Zhang, P.; Dai, S.; Xu, T.; Nie, Q. Network Structure in GeS 2 $-\mathrm{Sb}_{2} \mathrm{~S}_{3}$ Chalcogenide Glasses: Raman Spectroscopy and Phase Transformation Study. The Journal of Physical Chemistry C 2012, 116 (9), 5862-5867. https://doi.org/10.1021/jp208614j.

(22) Calvez, L.; Rozé, M.; Ledemi, Y.; Ma, H.-L.; Lucas, J.; Allix, M.; Matzen, G.; Zhang, X.-H. Controlled Crystallization in $\mathrm{Ge}-(\mathrm{Sb} / \mathrm{Ga})-(\mathrm{S} / \mathrm{Se})-\mathrm{MX}$ Glasses for Infrared Applications. Journal of the Ceramic Society of Japan 2008, 116 (1358), 1079-1082. https://doi.org/10.2109/jcersj2.116.1079.

(23) Adam, J.-L.; Zhang, X. Chalcogenide Glasses: Preparation, Properties and Applications; Woodhead Publishing, 2014.

(24) Wang, X. F.; Zhao, X. J.; Wang, Z. W.; Guo, H. T.; Gu, S. X.; Yu, J. G.; Liu, C. L.; Gong, Q. H. Thermal and Optical Properties of GeS2-Based Chalcogenide Glasses. Materials Science and Engineering: B 2004, 110 (1), 38-41. https://doi.org/10.1016/j.mseb.2004.02.008.

(25) Zhang, X. H.; Guimond, Y.; Bellec, Y. Production of Complex Chalcogenide Glass Optics by Molding for Thermal Imaging. Journal of Non-Crystalline Solids 2003, 326-327, 519-523. https://doi.org/10.1016/S0022-3093(03)00464-2.

(26) Saiter, A.; Delpouve, N.; Dargent, E.; Oberhauser, W.; Conzatti, L.; Cicogna, F.; Passaglia, E. Probing the Chain Segment Mobility at the Interface of Semi-Crystalline Polylactide/Clay Nanocomposites. European Polymer Journal 2016, 78, 274-289. https://doi.org/10.1016/j.eurpolymj.2016.03.040.

(27) Gault, B.; Vurpillot, F.; Vella, A.; Gilbert, M.; Menand, A.; Blavette, D.; Deconihout, B. DSIgn of a Femtosecond Laser Assisted Tomographic Atom Probe. Review of Scientific Instruments 2006, 77 (4), 043705. https://doi.org/10.1063/1.2194089.

(28) Miller, M. K. Atom Probe Tomography: Analysis at the Atomic Level; Springer Science \& Business Media, 2012.

(29) Tsong, T. T. Atom-Probe Field Ion Microscopy: Field Ion Emission, and Surfaces and Interfaces at Atomic Resolution; Cambridge University Press, 2005.

(30) Blum, I.; Cuvilly, F.; Lefebvre-Ulrikson, W. Atom Probe Sample Preparation. In Atom Probe Tomography; Elsevier, 2016; pp 97-121. https://doi.org/10.1016/B978-0-12-804647-0.000048.

(31) Zhu, S. Z.; Ma, H. L.; Matecki, M.; Zhang, X. H.; Adam, J. L.; Lucas, J. Controlled Crystallization of GeS2-Sb2S3-CsCl Glass for Fabricating Infrared Transmitting GlassCeramics. Journal of Non-Crystalline Solids 2005, 351 (40-42), 3309-3313. https://doi.org/10.1016/j.jnoncrysol.2005.07.016.

(32) Kim, H.; Choi, J.; Sohn, H.-J.; Kang, T. The Insertion Mechanism of Lithium into Mg2Si Anode Material for Li-Ion Batteries. J. Electrochem. Soc. 1999, 146 (12), 4401. https://doi.org/10.1149/1.1392650.

(33) Zhao, X.; Long, N.; Sun, X.; Yin, G.; Jiao, Q.; Liu, X.; Dai, S.; Lin, C. Relationship between Composition, Crystallization, and Phase Separation Behavior of GeS2-Sb2S3-CsCl Chalcogenide Glasses. Infrared Physics \& Technology 2019, 102, 102978. https://doi.org/10.1016/j.infrared.2019.102978. 
(34) Rivas, N. A.; Babayigit, A.; Conings, B.; Schwarz, T.; Sturm, A.; Garzón Manjón, A.; Cojocaru-Mirédin, O.; Gault, B.; Renner, F. U. Cryo-Focused Ion Beam Preparation of Perovskite Based Solar Cells for Atom Probe Tomography. PLoS ONE 2020, 15 (1), e0227920. https://doi.org/10.1371/journal.pone.0227920.

(35) Greene, M. E.; Kelly, T. F.; Larson, D. J.; Prosa, T. J. Focused Ion Beam Fabrication of Solidified Ferritin into Nanoscale Volumes for Compositional Analysis Using Atom Probe Tomography. Journal of Microscopy 2012, 247 (3), 288-299. https://doi.org/10.1111/j.13652818.2012.03644.x.

(36) Zanuttini, D.; Blum, I.; Rigutti, L.; Vurpillot, F.; Douady, J.; Jacquet, E.; Anglade, P.-M.; Gervais, B. Simulation of Field-Induced Molecular Dissociation in Atom-Probe Tomography: Identification of a Neutral Emission Channel. Phys. Rev. A 2017, 95 (6), 061401. https://doi.org/10.1103/PhysRevA.95.061401.

(37) Rigutti, L.; Venturi, L.; Houard, J.; Normand, A.; Silaeva, E. P.; Borz, M.; Malykhin, S. A.; Obraztsov, A. N.; Vella, A. Optical Contactless Measurement of Electric Field-Induced Tensile Stress in Diamond Nanoscale Needles. Nano Letters 2017, 17 (12), 7401-7409. https://doi.org/10.1021/acs.nanolett.7b03222.

(38) Lefebvre, W.; Vurpillot, F.; Sauvage, X. Atom Probe Tomography: Put Theory Into Practice; Academic Press, 2016.

(39) Hyde, J. M.; DaCosta, G.; Hatzoglou, C.; Weekes, H.; Radiguet, B.; Styman, P. D.; Vurpillot, F.; Pareige, C.; Etienne, A.; Bonny, G. et al. Analysis of Radiation Damage in Light Water Reactors: Comparison of Cluster Analysis Methods for the Analysis of Atom Probe Data. Microsc Microanal 2017, 23 (2), 366-375. https://doi.org/10.1017/S1431927616012678. 